\title{
The use of Unmanned Aerial Vehicle (UAV) for Tracking Stock Movements in Forest Enterprise Depots*
}

\author{
Remzi Eker $^{\text {*** }}$ iD, Abdurrahim Aydın² \\ ${ }^{1}$ Izmir Katip Çelebi University, Faculty of Forestry, 35620 İzmir, Turkey \\ ${ }^{2}$ Düzce University, Faculty of Forestry, 81620 Düzce, Turkey
}

\begin{abstract}
In forestry applications in Turkey, forest enterprise depots (FEDs) are permanent main places where forest products such as logs and round timbers are stored and presented for sale to the market. The principal functions of FEDs are receiving, classifying, protecting, preparing the forest products for the sales and tracking the stock movements. According to Communiqué No 288 on the Production of Fundamental Forest Products published by General Directorate of Forestry in Turkey, it is obligatory to conduct stocktaking twice a year in FEDs for tracking and controlling the stock movements. The capabilities of using Unmanned Aerial Vehicles (UAVs) in tracking stock movements in FEDs have not been extensively studied yet in the current literature. This study aimed to test UAVs in determining volume of round timber storages inside a FED named "Göl", located in Gölyaka District (Düzce, Turkey). A UAV flight was conducted and volume of round timber storage was calculated from point cloud, and compared to stock records for validation of UAV-based measurements. It was found that UAV-based volume measurements of the stock were quite compatible with available stock records. This study concluded that UAVs could be used in tracking stock movements in FEDs in an effective way.
\end{abstract}

Keywords: Forest Enterprise Depots, forest product, stock movement, UAV

\section{Introduction}

In last decade, Unmanned Aerial Vehicle (UAV) has gained popularity thanks to advantages of flexibility, low cost, reliability, autonomy, and capability of timely provision of high-resolution data (Zhang et al., 2016; Eker et al., 2018; Eker et al., 2019; Matese, 2020) in medium- and small-scale areas, and also have become an ever-expanding area in remote sensing applications (Yao et al., 2019). One of common applications of UAV remote sensing is forestry, since accurate information about forest composition, structure, volume, growth, and extent is essential for sustainable forest management (Tang and Shao, 2015). In fact, over the past few decades, remote sensing has gained increasing attention in forestry. The many applications of remote sensing in forestry were implemented such as monitoring, inventorying, and mapping of forest cover extent and its change (Ullah et al., 2016), volume, biomass, and carbon storage over time (Hopkinson et al., 2016), deforestation rates (Kamlun et al., 2016), the recovery after fire events (Chu and Guo, 2013), the forest degradation (Ghulam, 2014) and health (Hall et al., 2016), the growth trend (Boisvenue et al., 2016), the quantity of the carbon stored in soil (Kumar et al., 2016), the impact of climate change (Srivastava et al., 2015), the level of biodiversity (Schäfer et al., 2016), the forest structural types (Torresan et al., 2016), the ecological interactions between the structural and functional components
(Steinaker et al., 2016), and forest road related studies (Buğday, 2018; Turk et al., 2019a, 2019b).

The use of UAV technology in the scope of forestry studies can also be summarized as; (1) the estimation of dendrometric information, (2) classification of tree species, (3) the determination of forest spaces, (4) postfire observation and measurements, (5) forest protection and health mapping, and (6) post-harvest stand damages (Torresan et al., 2017). Even though several types of forestry applications have been studied in literature, there is no extensive study testing the usability of UAV remote sensing in tracking stock movements in forest enterprise depots (FEDs). FEDs are areas for potentially large volume of forest products such as logs and round timbers to be stored and/or handled prior to transportation to processing sites or other intermediate and final locations. The principal functions of FEDs are receiving, classifying, protecting, preparing of the forest products for the sales and tracking their stock movements (Gümüskaya, 1978). The forest products transported from the forest or temporary depots are delivered in accordance with the shipment scrip. Forest products delivered to FED are then classified by tree species, dimensions and appearance characteristics (Kantay and Köse, 2009). This classification should be determined by considering market conditions and the clients' demands. In this process, the type, class and quantity of each forest product in FED should be

\footnotetext{
${ }^{*}$ This work has been partially presented in FETEC2019 Symposium

**Author: Tel: +90 232 3293535/5227 E-mail: remzi.eker@ikc.edu.tr 
identified, which indicates the importance of tracking the stock movements (Gümüşkaya, 1978). According to Communiqué No 288 on the Production of Fundamental Forest Products published by General Directorate of Forestry in Turkey, it is required to perform stocktaking twice a year in FEDs in order to track and control the stock movements.

The combination of UAV-images and structure from motion (SfM) algorithm provides an efficient, low-cost and rapid framework for the remote sensing and monitoring of dynamic natural environments (Clapuyt et al., 2016). In forestry studies, in general, a set of highresolution overlapped images is used to generate digital surface models (DSMs) and orthophotos by applying SfM techniques. Although the SfM algorithm has been used in various forms since 1979 (Ullman, 1979), it began to be commonly applied in the early 2000 s (Snavely et al., 2008). Today, SfM is regarded as a photogrammetric method for creating 3D (threedimensional) models of a feature or topography from overlapping 2D photos taken from many locations and orientations in order to reconstruct the photographed scene (Shervais, 2015). The SfM process starts by acquiring images with sufficient overlap (e.g., 80-90\%) from multiple positions and/or angles (Lucieer et al., 2014).

In the present study, it was aimed to test the usability of UAV systems in tracking stock movements in FED as a forestry application. Main components of FED are stowage, and they form a mass that volume could be estimated by UAV. This initial study was thus aimed to calculate volume of each timber stowage in a FED and compare them with actual stock records. That's why, this study presents a preliminary works integrating UAV technology to a forestry application.

\section{Material and Methods}

\subsection{Study Area}

A FED named "Göl", located at near the lake Efteni in Gölyaka District (Düzce, NW Turkey) was selected as the study area for determining volume of round timber stowage with UAV technology. The location map is given in Figure 1. The latitude and longitude of the FED are $40^{\circ} 45^{\prime} 22.71^{\prime \prime} \mathrm{N}-31^{\circ} 33^{\prime} 33.96^{\prime \prime} \mathrm{E}$ and $40^{\circ} 45^{\prime} 13.09^{\prime \prime} \mathrm{N}-31^{\circ}$ 4'2.41"E in WGS84 spatial coordinate system. The FED, where the round timber products comes from surrounding forests, covers 5.1 ha area. For the years of 2006, 2007, and 2008, the volume stocked in FED was $15162 \mathrm{~m}^{3}$, $14073 \mathrm{~m}^{3}$, and $23858 \mathrm{~m}^{3}$, respectively (Selmi, 2009).
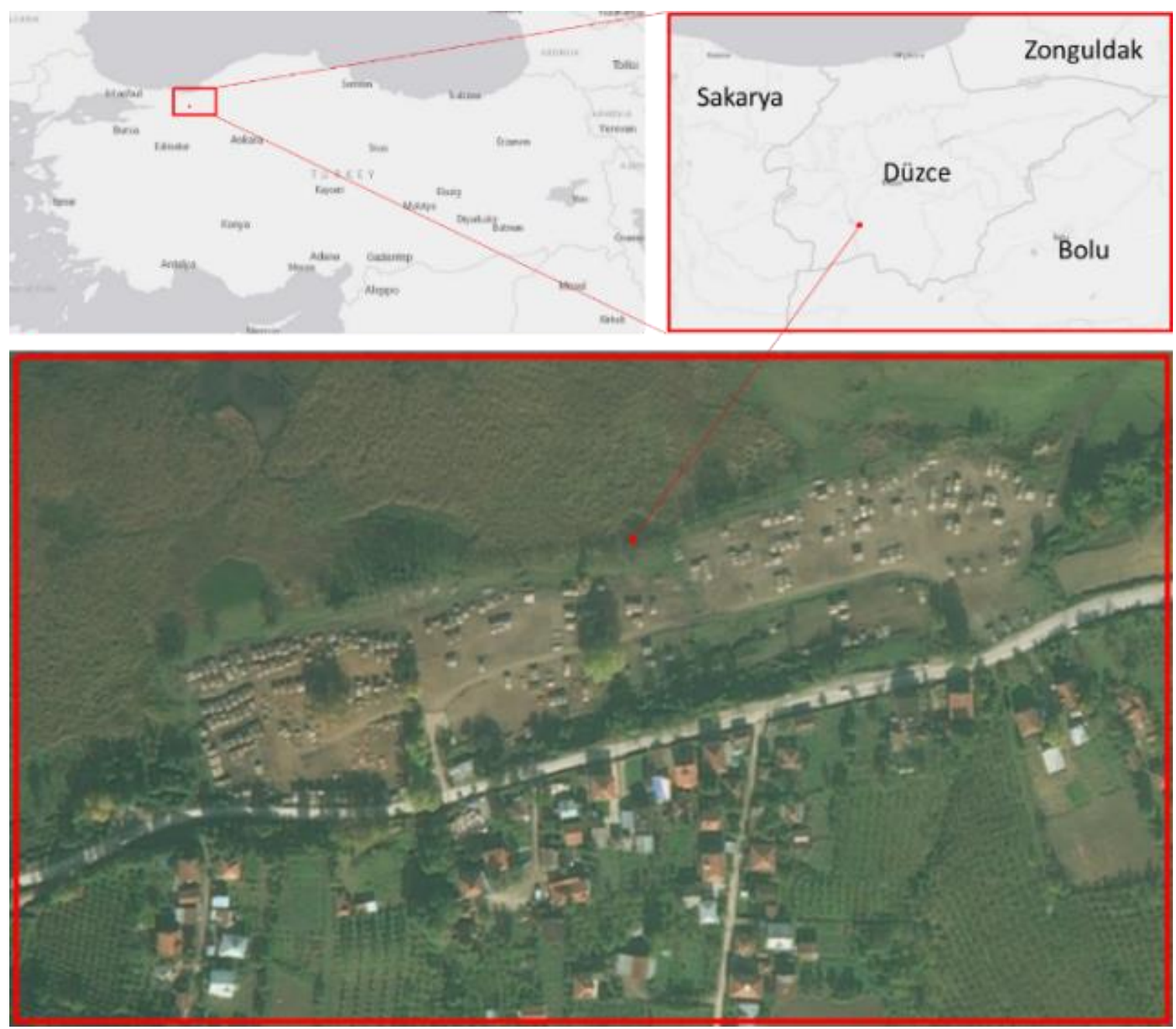

Figure 1. Location of FED named "Göl" 
2.2. UAV Data Acquisition and Processing for Calculation of Stock Volume

In this study, one UAV flight was conducted over the FED on $8^{\text {th }}$ August 2019, and volume of round timber stowage was calculated from high-resolution UAV data. The main steps of the workflow of the UAV-based image acquisition can be categorized as follows 1) off-site preparation, 2) on-site preparation and image acquisition, and 3) post-processing. The off-site preparation included collecting data about the area and planning the UAV flight. The UAV flight mission was prepared by using Universal Ground Control Software (UgCS) version 2.13.519 (Figure 2). The flight mission was planned as the platform flies at $50 \mathrm{~m}$ altitude, with both side and forward overlapped rates of $80 \%$. The planned flight mission took about 16 minutes, and drone flied about $4.2 \mathrm{~km}$. In total,
290 images with ground sampling distance (GSD) of 1.64 $\mathrm{cm} /$ pixel were taken.

On-site preparation and image acquisition stage includes flights and field works. In total 10 ground control points (GCPs) were surveyed with centimeter accuracies less than $3 \mathrm{~cm}$ by using SATLAB SL600 GNSS receiver (Figure 3). The UAV flight mission was conducted using an off-the-shelf platform called DJI Mavic Pro which has an integrated CMOS sensor with a resolution of $12 \mathrm{MP}$ (Figure 4). Post processing includes applying the SfM algorithm to generate the DSM and orthophoto, using Agisoft Metashape Professional. The workflow in Metashape is described as (1) adding images; (2) alignment of the images; (3) defining of GCPs and building dense cloud; and (4) exporting dense point cloud, DSM and orthomosaic (Figure 5).

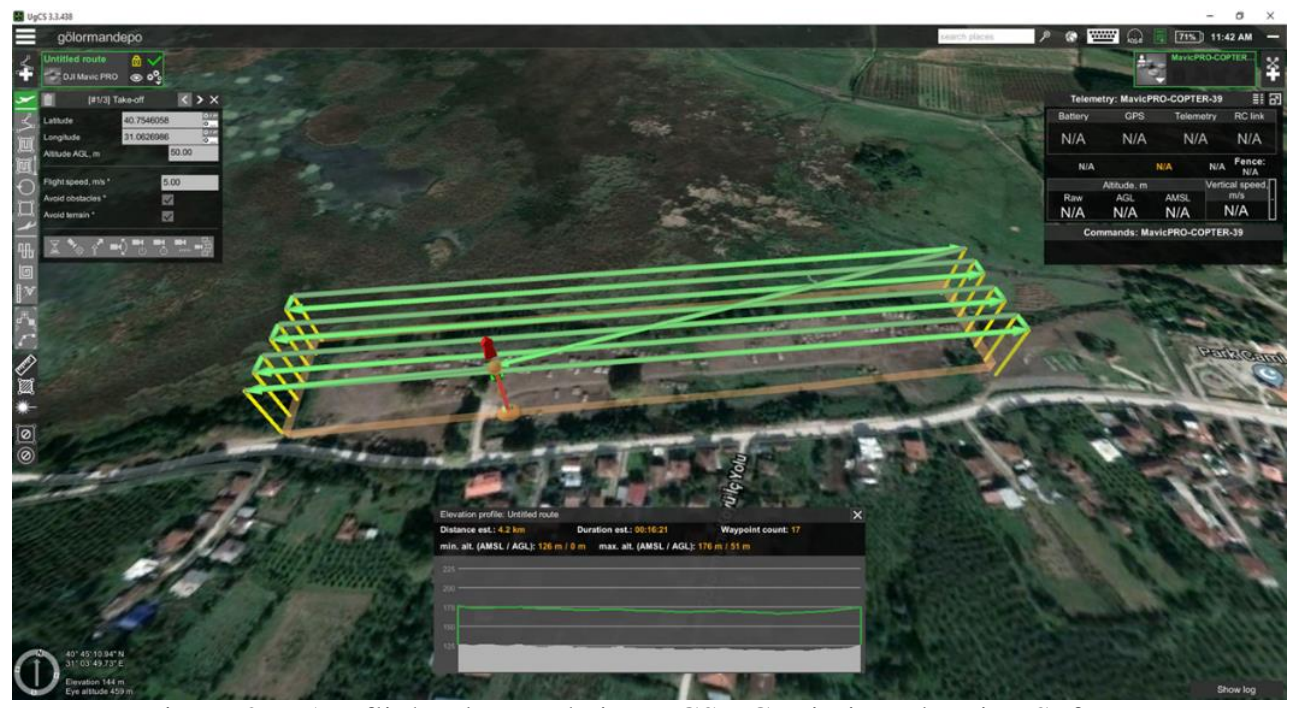

Figure 2. UAV flight plan made in UgCS PC Mission Planning Software

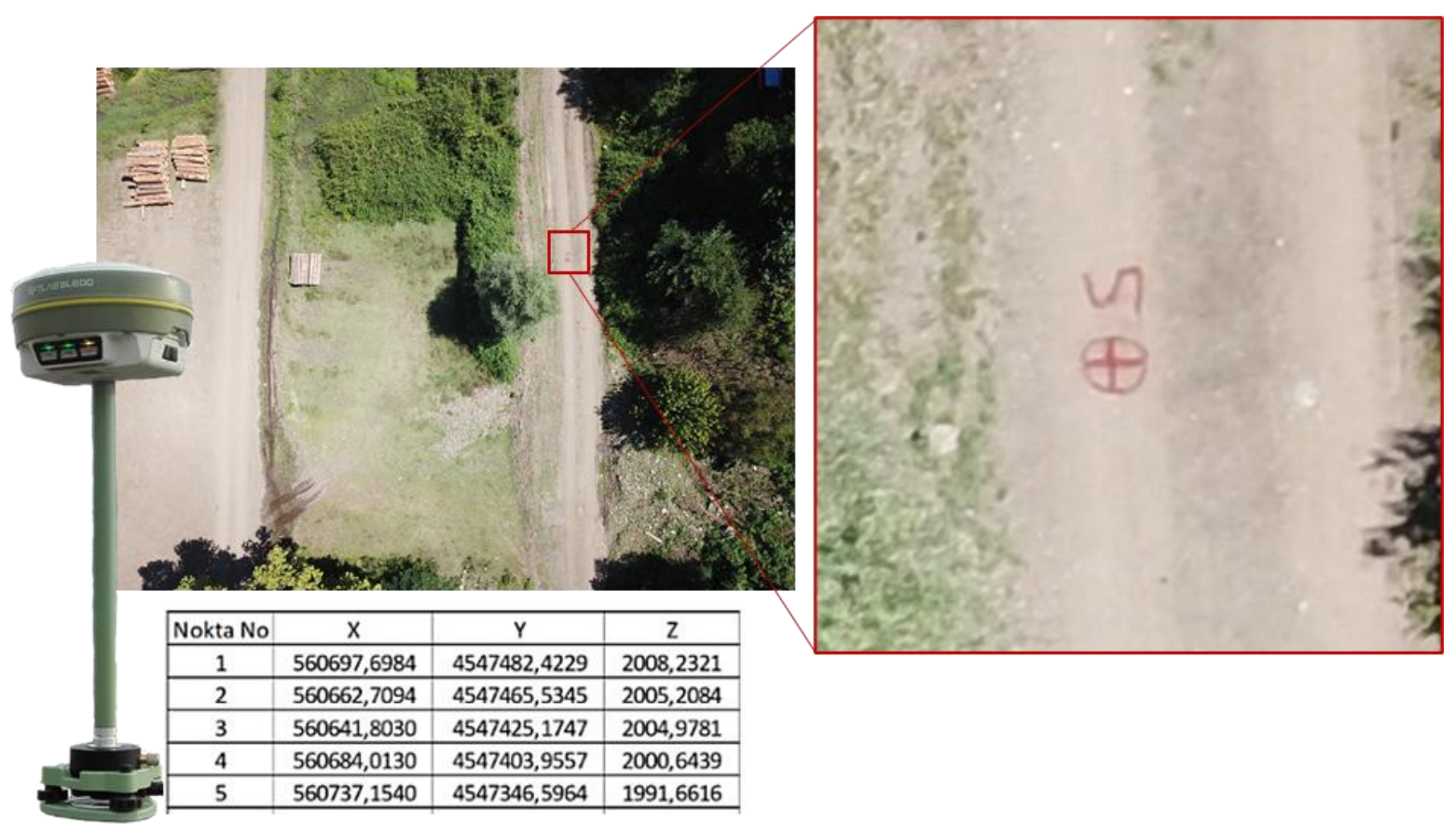

Figure 3. Sample GCP surveyed in the study 


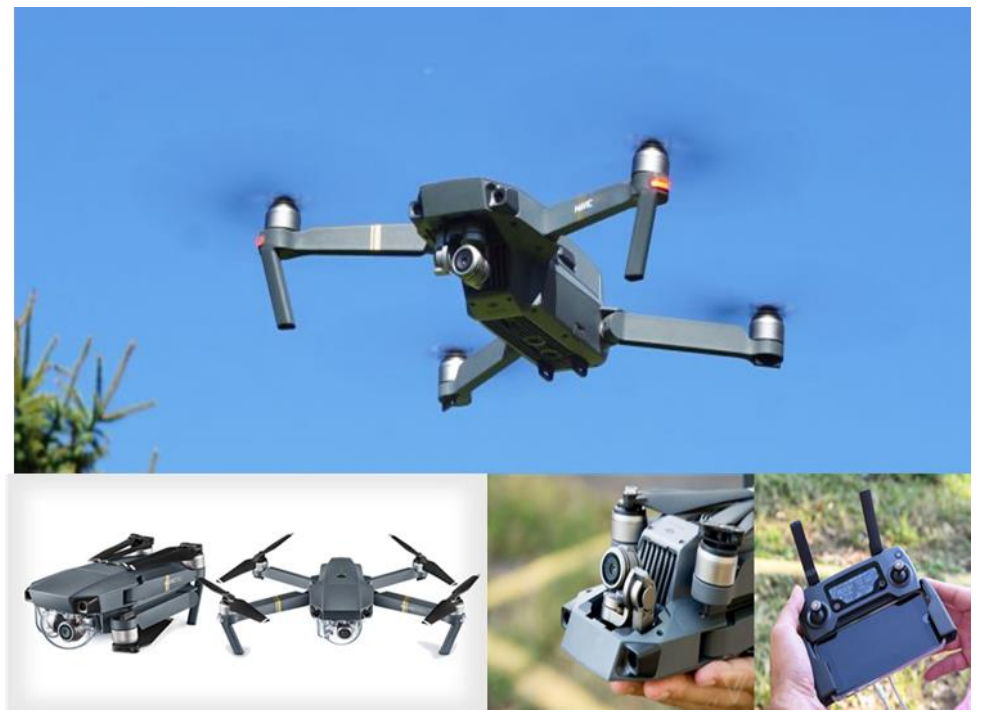

Figure 4. UAV platform used in the study

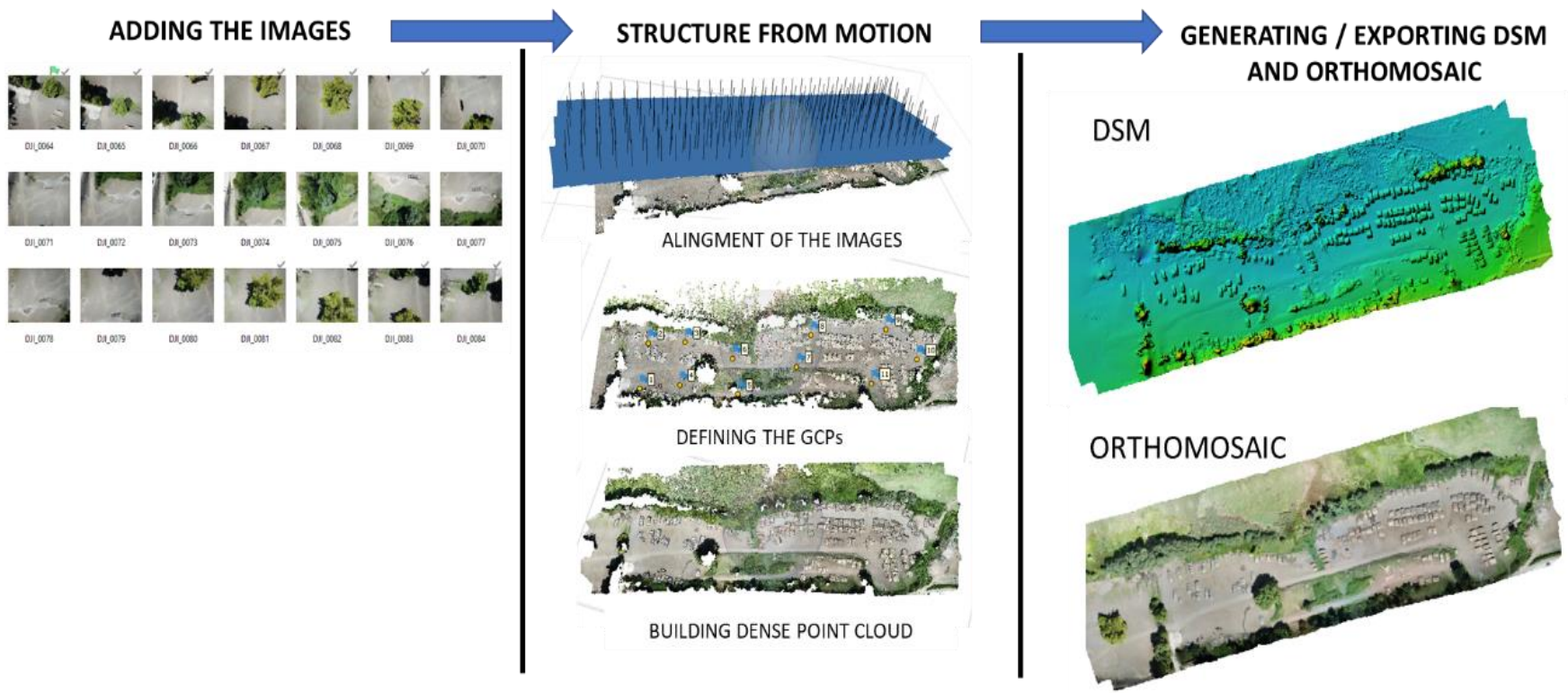

Figure 5. The data processing workflow in Metashape

Calculation of stock volume in the FED was made in several steps. The basic input used for calculation of stock volume is dense point cloud. Firstly, points in the dense cloud located outside of the FED area were removed manually in order for decreasing number of points for faster analysis (Figure 6). Remaining points was firstly classified by using automatic classification tool in Metashape as three classes: Ground, Highvegetation, and Man-made (corresponding to timber stowage) (Figure 6). Since the classified made in Metashape did not provide a complete classification of stowage, the points belonging to timber stowage was firstly filtered (Figure 7) to refine the results by reclassifying in CloudCompare, which is a freely available, open-source, 3D point cloud and mesh processing software (http://www.danielgm.net/cc/). For this aim the CANUPO (CAractérisation de NUages de POints) plug-in for CloudCompare was applied. The CANUPO plug in was designed by Brodu and Lague
(2012) for binary classification of point clouds in complex natural environments using a multi-scale dimensionality criterion. This plug-in uses two steps for point cloud classification: 1) training classifiers, and 2) classifying clouds. During the classification with CANUPO, first, samples of points (i.e., classifiers) belonging to two classes (stowage and other) were collected in CloudCompare to produce training datasets. Then, the classification was made based on the training data. The re-classified cloud is given in Figure 8.

After obtaining points representing correctly the class "stowage", a segmentation was applied to each stowage, and then volume of each stowage was calculated by converting segmented point clouds to meshes in CloudCompare (Figure 8). In the present study, the volume of only five stowages selected in FED were calculated and compared with stock records, which were obtained from the person who responsible for stocktaking in FED. 

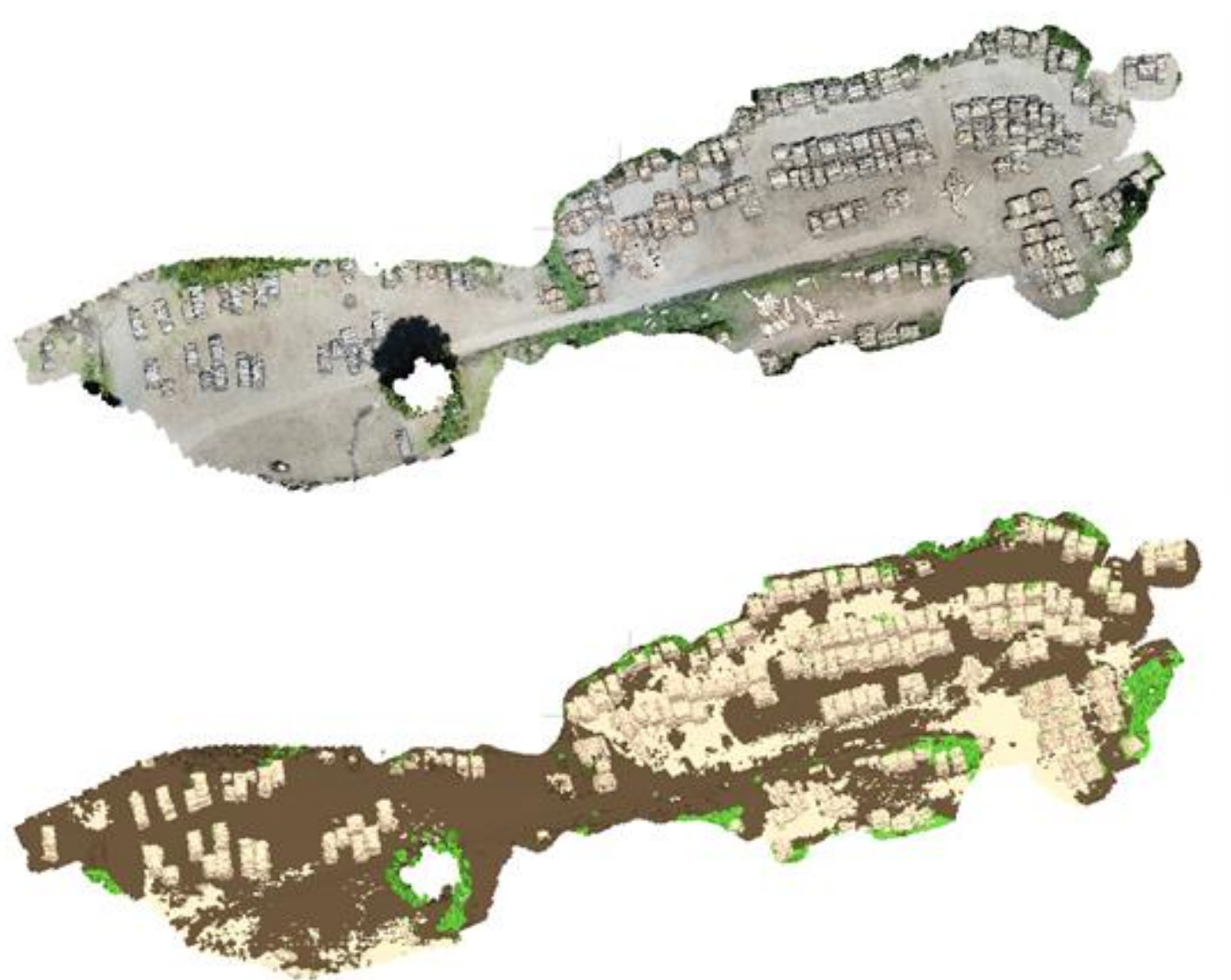

Figure 6. Dense point cloud (upper) and dense point cloud classified (bottom) into three classes such as ground (brown), highvegetation (green), and man-made (corresponding to timber stowage) (white)

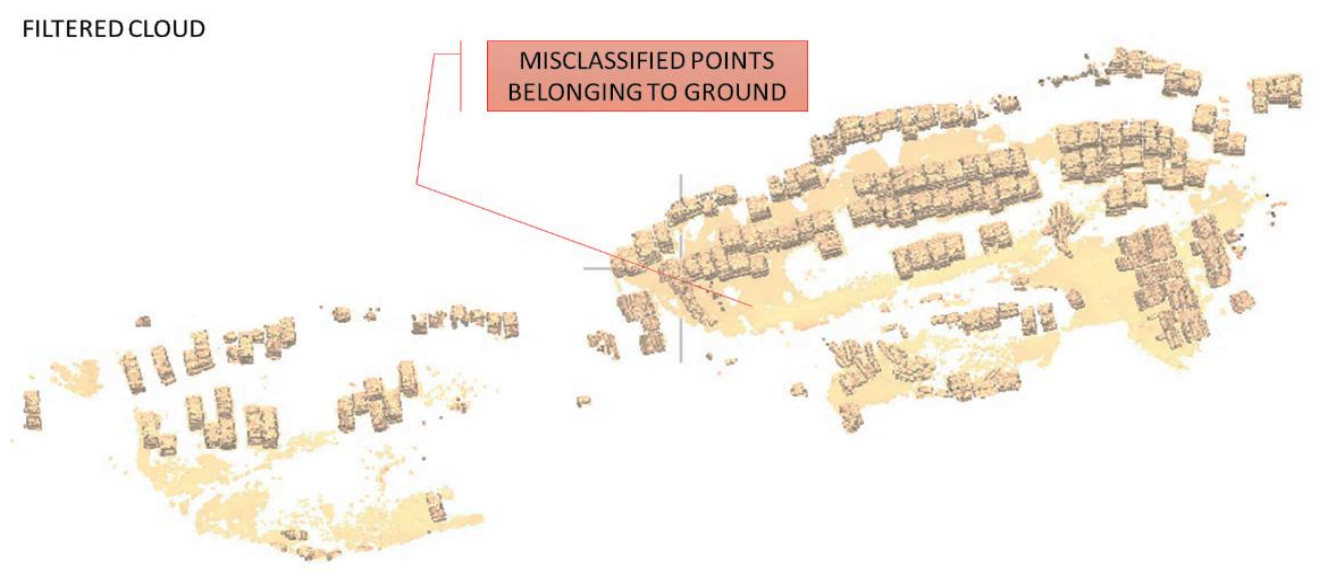

Figure 7. Dense point cloud filtered by class values (The point cloud includes misclassified points belonging to class "ground")

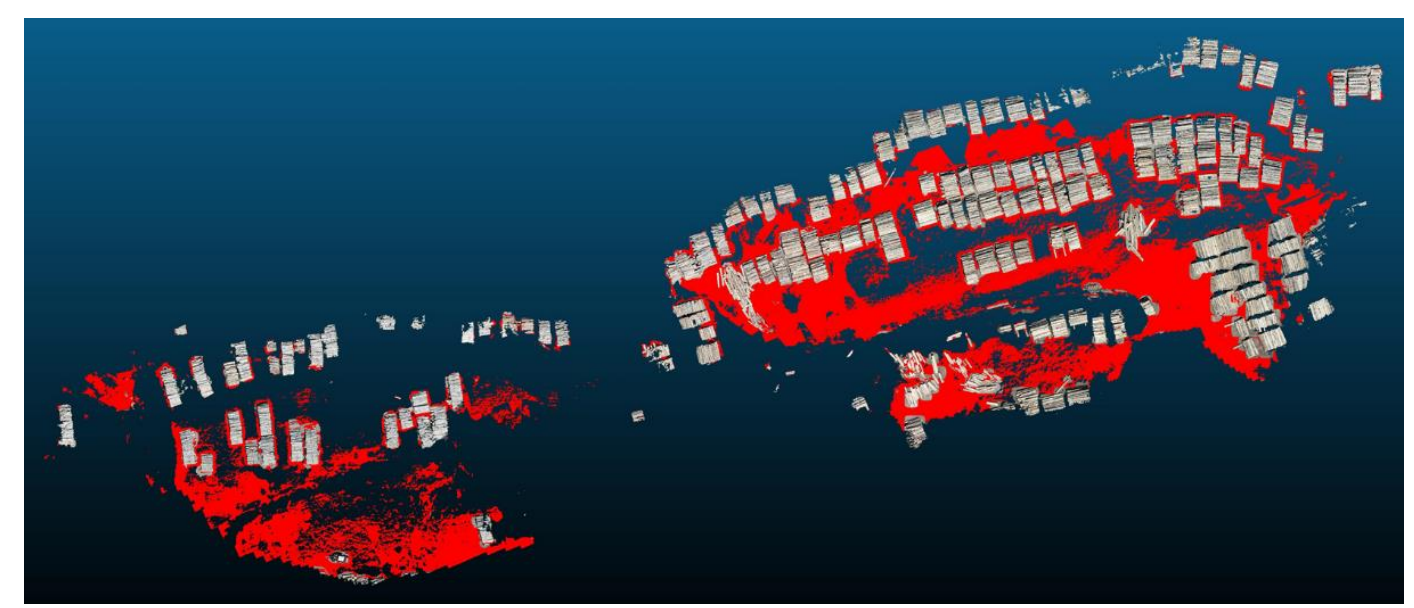

Figure 8 . Refined point cloud by reclassifying with CANUPO 


\section{Result and Discussion}

In this study, a UAV flight was conducted on FED for testing UAV capabilities in determining timber volume. The SfM process was applied to obtain dense point cloud, very high-resolution DSM and orhomosaic. The generated DSM and orthomosaic have spatial resolutions of $3.29 \mathrm{~cm}$ and $1.64 \mathrm{~cm}$, respectively (Figure 9). In this study, however, dense point cloud was used to calculate timber volume. The point cloud was obtained as very densely in terms of number of points, which includes more than 40 million of points. Then, the point cloud was classified and segmented to generate meshes for each stowage. In this study, calculated volume of five selected timber stowages was compared to stock records (Table 1). The set of selected timber stowage is shown in Figure 10Figure 14.
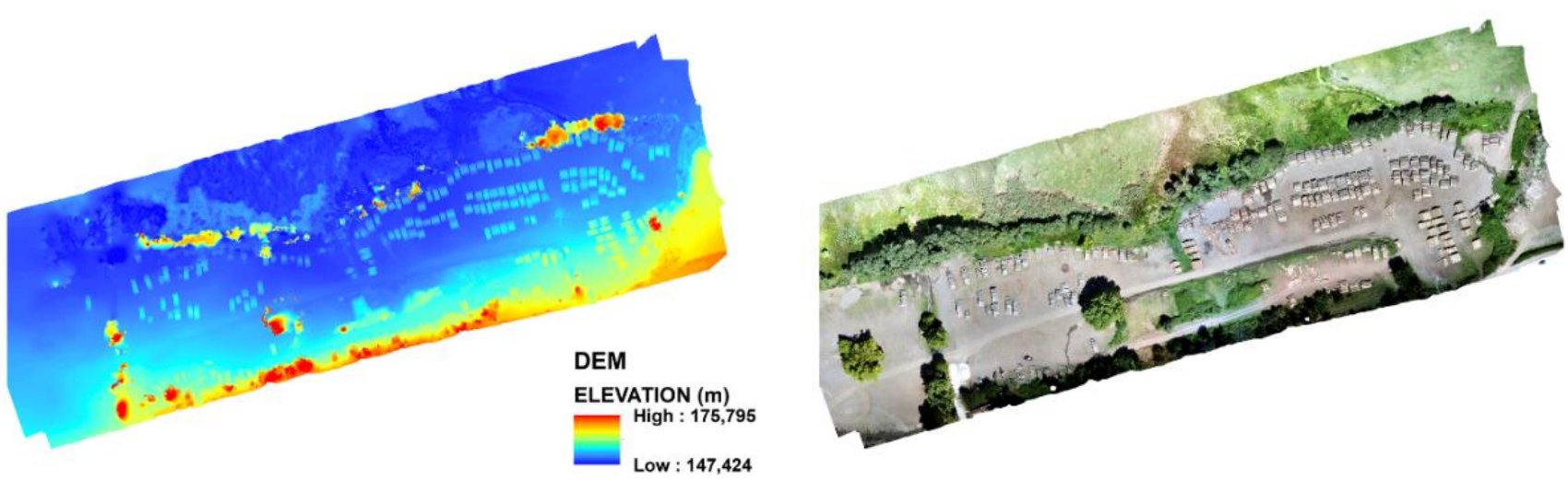

Figure 9. DSM and orthomosaic produced by SfM from UAV images

Table 1. Results of comparison of the calculated volume and volume in stock

\begin{tabular}{ccccc}
\hline $\begin{array}{c}\text { No of Timber } \\
\text { Stowage in FED }\end{array}$ & $\begin{array}{c}\text { Number of Timber } \\
\text { in Stowage }\end{array}$ & $\begin{array}{c}\text { Volume Calculated } \\
\mathrm{m}^{3}(\mathrm{~A})\end{array}$ & $\begin{array}{c}\text { Volume in Stock } \\
\mathrm{m}^{3}(\mathrm{~B})\end{array}$ & $\begin{array}{c}\text { Difference } \\
(\mathrm{B})-(\mathrm{A})\end{array}$ \\
\hline 193 & 73 & 35.096 & 35.658 & 0.562 \\
268 & 70 & 41.681 & 41.836 & 0.155 \\
274 & 59 & 34.508 & 34.790 & 0.282 \\
269 & 58 & 33.148 & 32.893 & -0.255 \\
283 & 43 & 39.020 & 43.422 & 4.402 \\
\hline
\end{tabular}

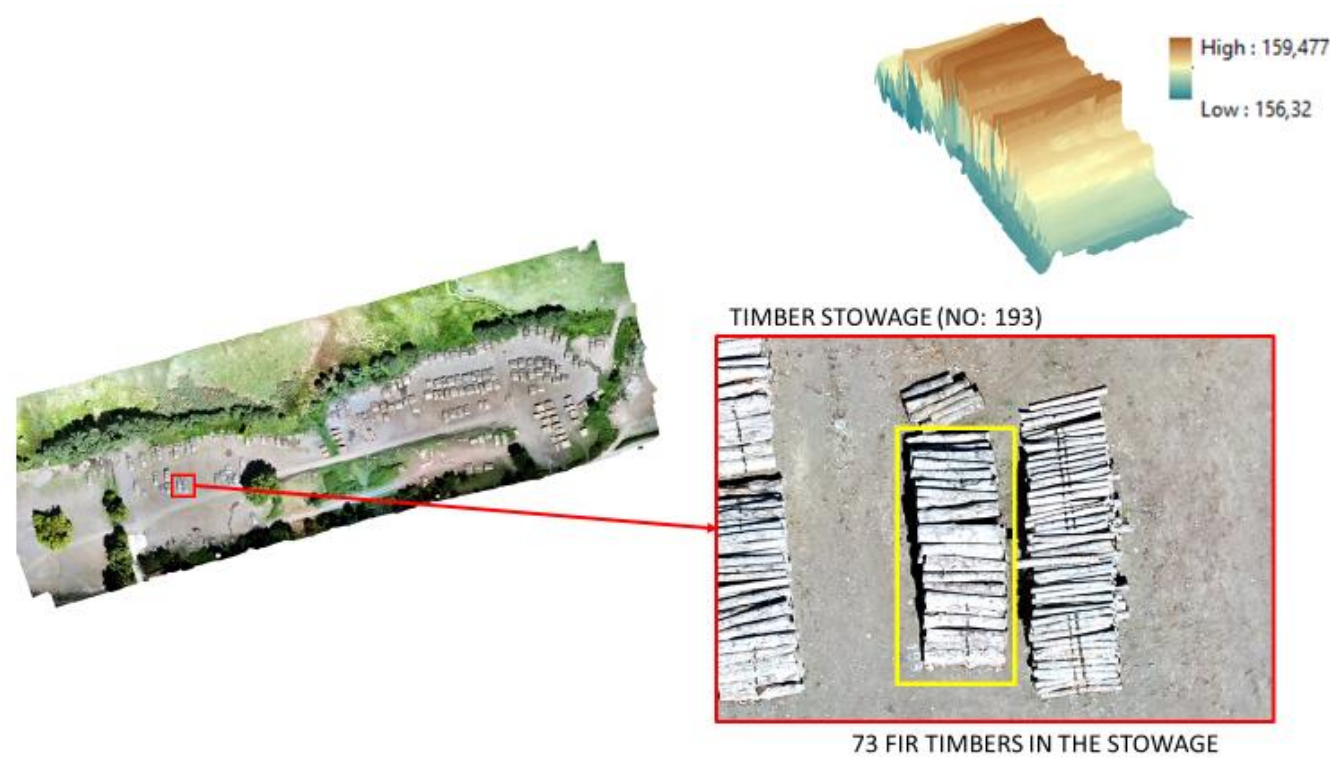

Figure 10. Timber stowage (No: 193) used for volume comparison 

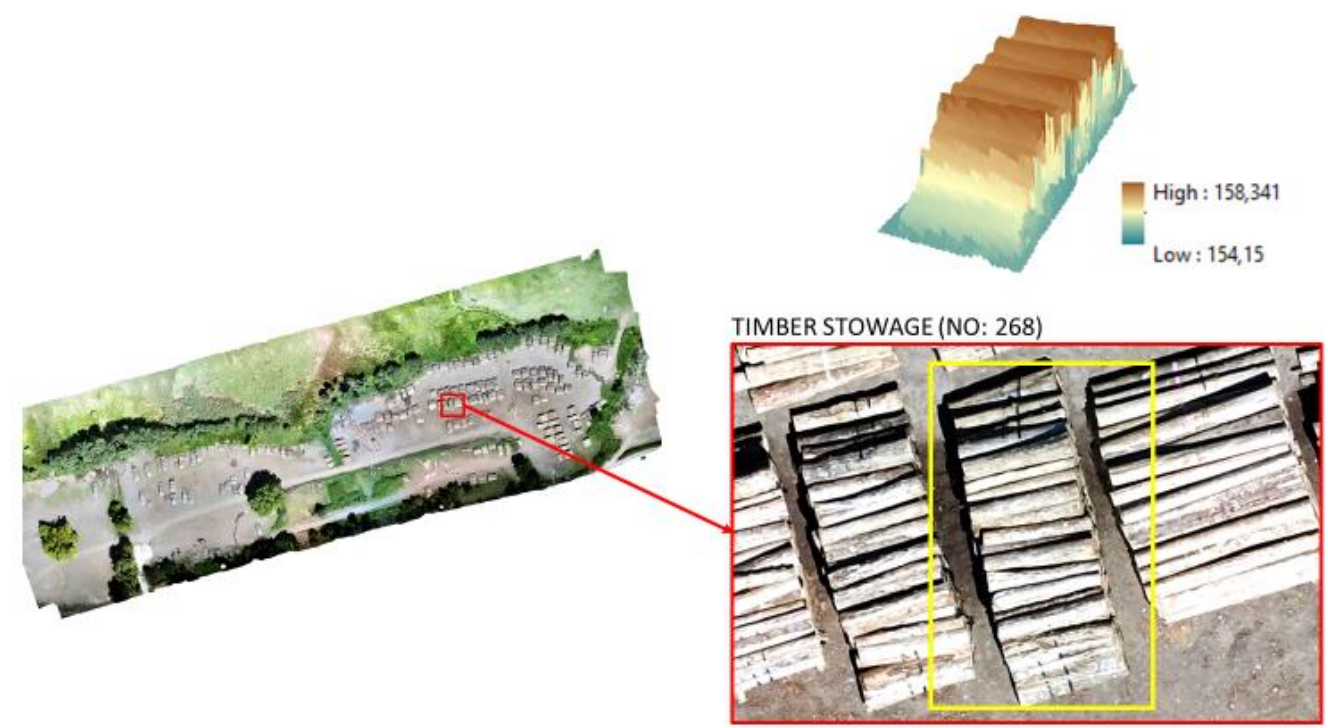

70 FIR TIMBERS IN THE STOWAGE

Figure 11. Timber stowage (No: 268) used for volume comparison

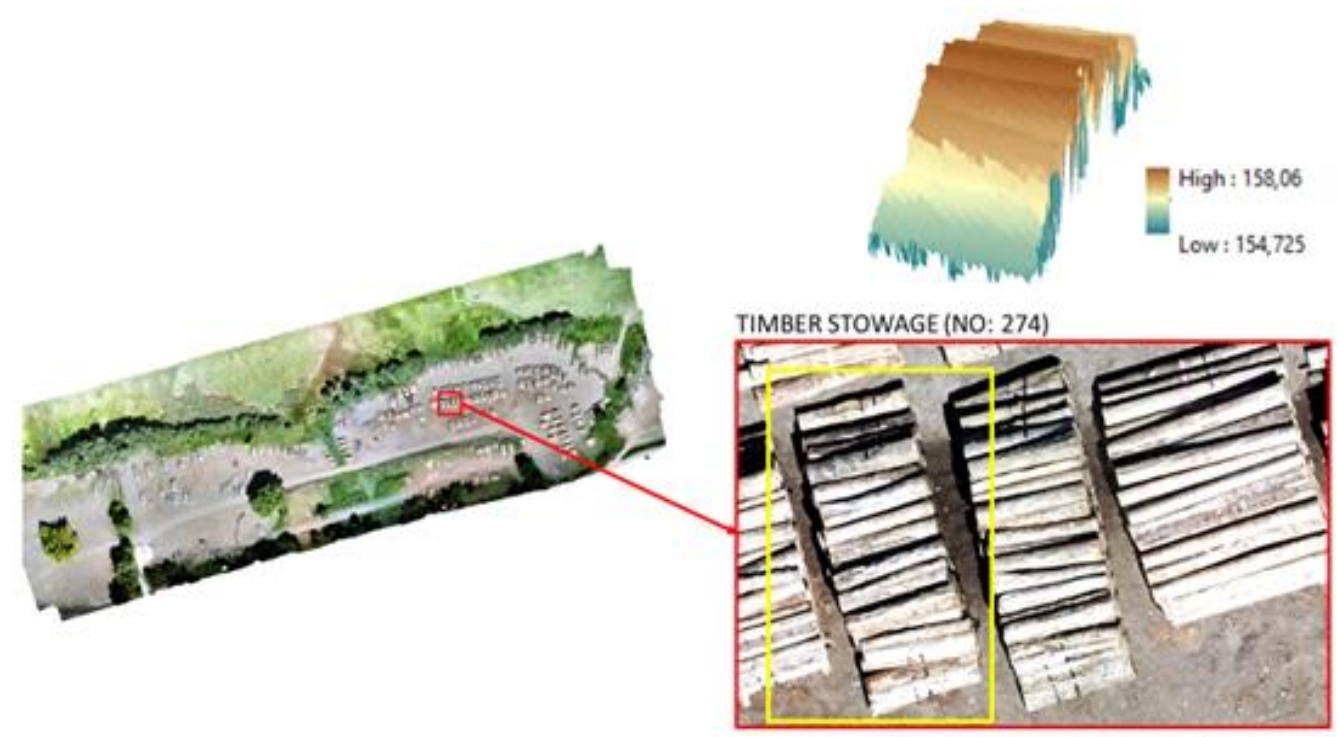

59 FIR TIMBER IN THE STOWAGE

Figure 12. Timber stowage (No: 274) used for volume comparison

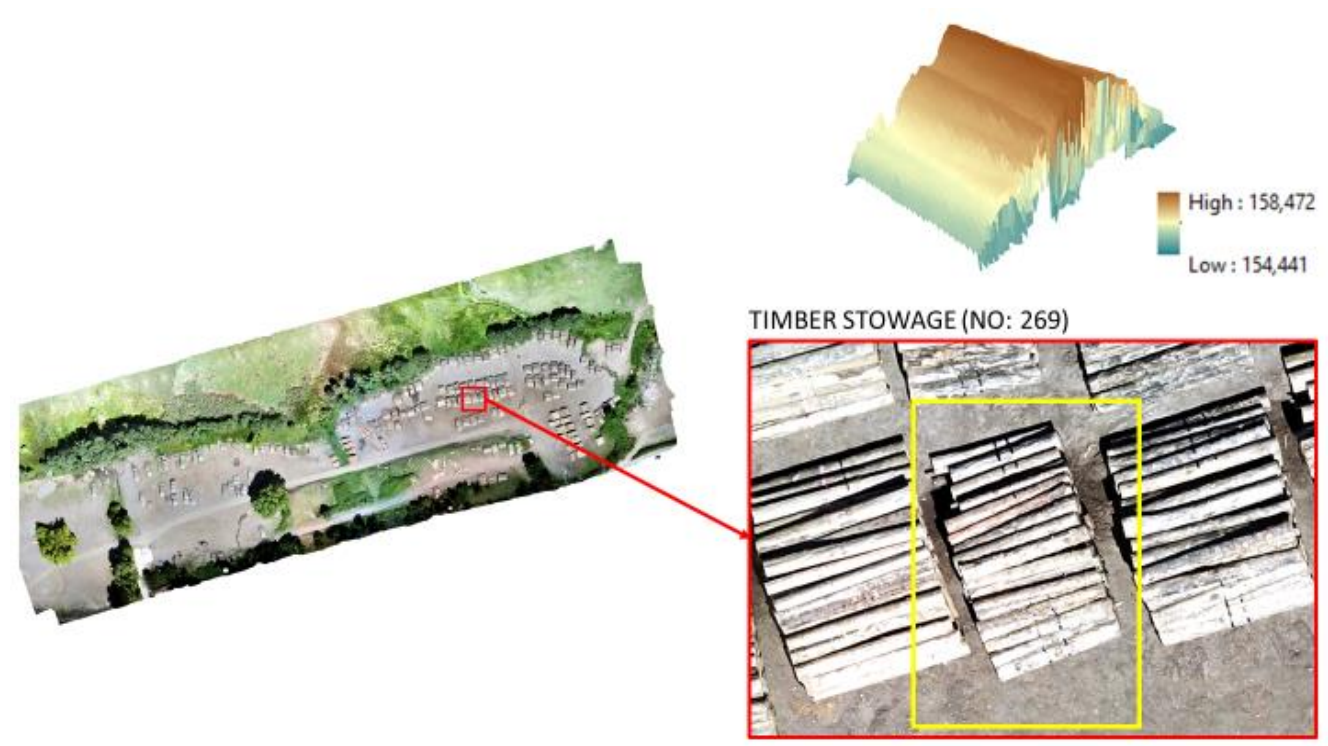

58 FIR TIMBERS IN THE STOWAGE

Figure 13. Timber stowage (No: 269) used for volume comparison 


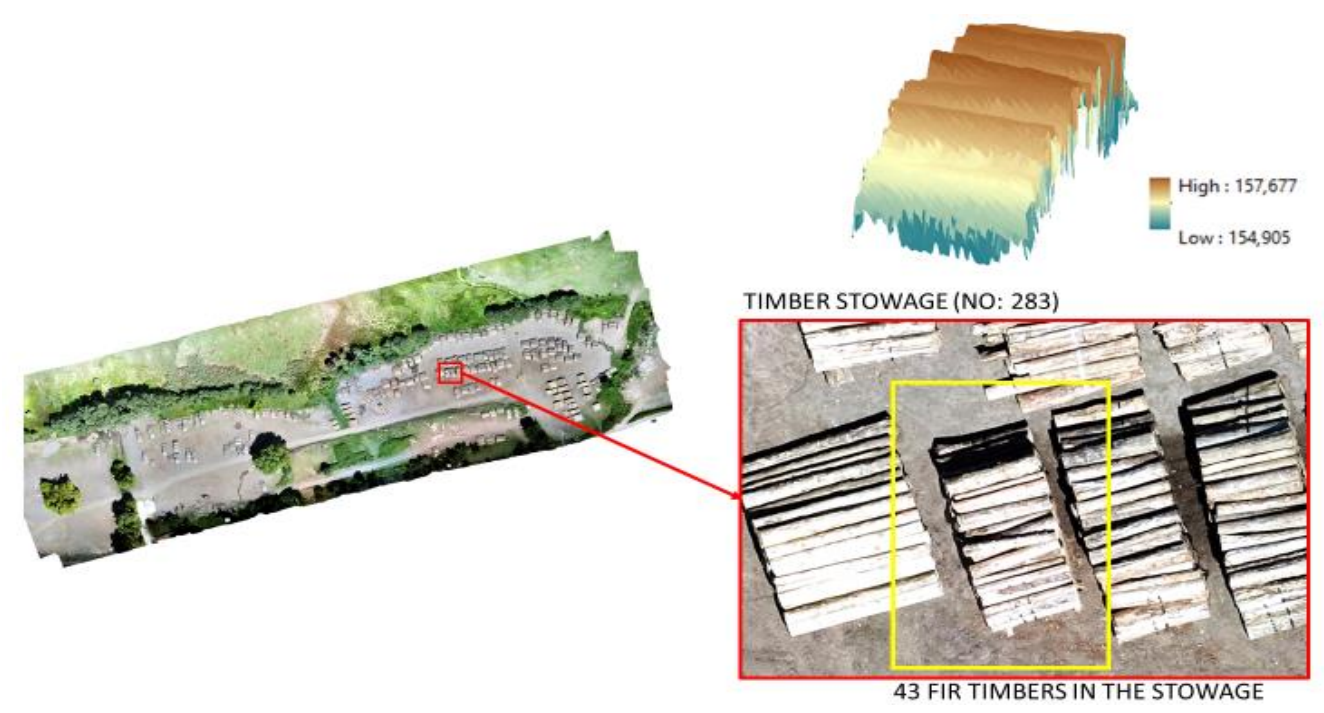

Figure 14. Timber stowage (No: 283) used for volume comparison

According to results, UAV based volume calculations were obtained as quite compatible with volumes in stock. The UAV based volumes were differed in values between $-0.255 \mathrm{~m}^{3}$ and $4.402 \mathrm{~m}^{3}$. The difference between UAV based volume and volume in stock can be due to many factors. First of all, each stowage should be placed as visible in FED, since autonomous flight was carried out for taking images in nadir-view angles. Another important factor is flight altitude in point of sensor quality (12 MP in this study) affecting the spatial resolution. In the present study, $50 \mathrm{~m}$ flight altitude provided $1.64 \mathrm{~cm}$ GSD which is quite adequate for modelling of each timber stowage. The lower or higher altitudes of flight could be tested for more understanding how a role the altitude change play. However, more important point in image taken scenario is nadir-view angle of the sensor. In this study, UAV images was taken only in nadir-view angle. Correspondingly, the lateral surfaces of objects were not represented by any point in the cloud. The null geometry of lateral surfaces of objects resulted data loss. Even this data loss can be managed by generating meshes, it affects the classification process adversely. Although more advanced classification methods such as random forest classification and deep learning methods could be used to get more correct classification, such data loss causes differences between calculated volume and volume in stock. Oblique photogrammetry in taking images by UAV could be used by both autonomous and manual flights to minimize such data losses caused by taking images in nadir-view angles. Because many studies (e.g. Aicardi et al., 2016; Vacca et al., 2017) revealed that oblique images provide improved $3 \mathrm{D}$ models of complex structures such as cities including façades and building footprints. Another factor is how actual volume of a stowage in stock is calculated by traditional method. In general, the volume of a stowage equals to sum of volume of timbers in stowage. The volume of each timber is also calculated by length and radius information. That's why, gaps in the stowage could vary in percentage and cause difference between calculated volume and volume in stock since UAV based model is solid (Figure 15). In addition, the method of installing a stowage, i.e. whether it is installed on additional timber to lift it from ground or not, affects the results because these additional timbers do not include total volume of stowage in stock on the contrary of UAV models (Figure 15).

\section{Conclusions}

Depending on recent developments in UAV technology and related methodologies, its use in forestry application has been increasing. Even so, UAV-based volume measurements of the stock in FEDs have not tested in literature. That's why, this study aimed to test initially the usage possibility of UAV for tracking stock in FEDs by determining timber volume in a FED. It was concluded that UAVs could be used in tracking stock movements in FEDs in an effective way. However, in this study, a semi-automatic method was applied for initial tests. The flexibility of UAV remote sensing in image acquisition allowing to conduct flight any time on-demand is most important advantage along with its low-costs.

For future works, more comprehensive studies in tracking stock movements in FEDs would be made to eliminate limitations in this study. Especially, advanced classification methods for point clouds, such as deep learning methods, could be focused point. Another objective is to develop a more comprehensive methodology allowing the fully automatization of all steps in calculation of volumes of stowage. Besides, UAV remote sensing could compare to alternative terrestrial close range or oblique photogrammetric systems. In addition, detecting of stowage and extracting their information by using not only from point cloud but also images would be tested. The recent developments in UAV technology and its remote sensing applications allow to make different type of studies in forestry applications. The more comprehensive integration of the UAV technology to forestry studies will be key point in opening new horizons for researcher and practitioners by contributing them in the manner of positive development. 

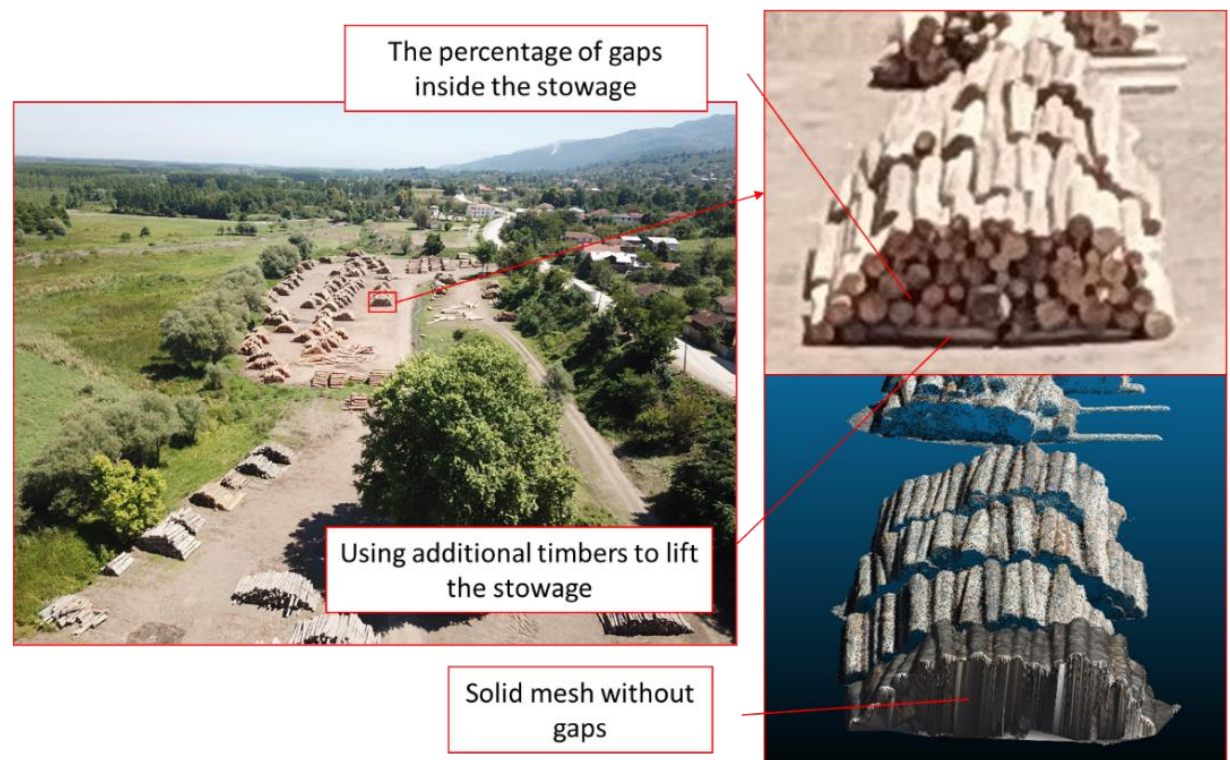

Figure 15. The gaps inside the stowage and additional timbers used to lift the stowage from ground

\section{Ethics Committee Approval: N/A.}

Peer-review: Externally peer-reviewed.

Author Contributions: Concept: R.E. and A.A.; Design: R.E.; Supervision: A.A.; Resources: R.E. and A.A.; Data Collection: R.E.; Analysis: R.E.; Literature Search: R.E.; Writing Manuscript: R.E.; Critical Review: A.A.

Conflict of Interest: The authors have no conflicts of interest to declare.

Financial Disclosure: The authors declared that this study has received no financial support

Cite this paper as: Eker, R., Aydın, A., 2020. The use of Unmanned Aerial Vehicle (UAV) for Tracking Stock Movements in Forest Enterprise Depots. European Journal of Forest Engineering, 6(2): 68-77.

\section{References}

Aicardi, I., Chiabrando, F., Grasso, N., Lingua, A.M., Noardo, F., Spano, A. 2016. UAV photogrammetry with oblique images: first analysis on data acquisition and processing. The International Archives of the Photogrammetry, Remote Sensing and Spatial Information Sciences, Volume XLI-B1, 2016 XXIII ISPRS Congress, 12-19 July 2016, Prague, Czech Republic, pp. 835-842.

Boisvenue, C., Smiley, B.P. White, J.C. Kurz, W.A., Wulder. M.A., 2016. Integration of Landsat Time Series and Field Plots for Forest Productivity Estimates in Decision Support Models. Forest Ecology and Management, 376: 284-297.

Brodu, N., Lague, D., 2012. 3D Terrestrial lidar data classification of complex natural scenes using a multi-scale dimensionality criterion: Applications in geomorphology. ISPRS J. Photogramm. Remote Sensing, 68, 121-134.
Buğday, E., 2018. Capabilities of using UAVs in forest road construction activities. Eur J Forest Eng, 4(2): 56-62.

Chu, T., Guo, X., 2013. Remote Sensing Techniques in Monitoring Post-Fire Effects and Patterns of Forest Recovery in Boreal Forest Regions: A Review. Remote Sensing, 6 (1): 470-520.

Clapuyt, F., Vanacker, V., Oost, K.V., 2016. Reproducibility of UAV-based earth topography reconstructions based on Structure-from-Motion algorithms. Geomorphology, 260, 4-15.

Eker, R., Aydın, A., Hübl, J. 2018. Unmanned aerial vehicle (UAV)-based monitoring of a landslide: Gallenzerkogel landslide (Ybbs-Lower Austria) case study. Environmental Monitoring and Assessment, 190:28.

Eker, R., Bühler, Y., Schlögl, S., Stoffel, A., Aydın, A., 2019. Monitoring of snow cover ablation using very high spatial resolution remote sensing datasets. Remote Sensing, 11, 699.

Ghulam, A., 2014. Monitoring Tropical Forest Degradation in Betampona Nature Reserve, Madagascar Using Multisource Remote Sensing Data Fusion. IEEE Journal of Selected Topics in Applied Earth Observations and Remote Sensing, 7 (12): 4960-4971.

Gümüşkaya, İ., 1978. The role of forest depots in marketing and applications in Turkey (original in Turkish). PhD Thesis, İstanbul University, Institute of Natural and Applied Sciences.

Hall, R.J., Castilla, G., White, J.C., Cooke, B.J., Skakun, R.S., 2016. Remote Sensing of Forest Pest Damage: A Review and Lessons Learned from A Canadian Perspective. The Canadian Entomologist, 1-61.

Hopkinson, C., Chasmer, L. Barr, A.G., Kljun, N., Black, T.A., McCaughey. J. H., 2016. Monitoring Boreal Forest Biomass and Carbon Storage Change by Integrating Airborne Laser Scanning, Biometry and 
Eddy Covariance Data. Remote Sensing of Environment, 181 (2016): 82-95.

Kamlun, K.U., Arndt, R.B., Phua, M.H., 2016. Monitoring Deforestation in Malaysia between 1985 and 2013: Insight from South-Western Sabah and Its Protected Peat Swamp Area. Land Use Policy, 57 (2016): 418-430.

Kantay, R., Köse, C., 2009. Forest enterprise depots and storage techniques (original in Turkish). Journal of the Faculty of Forestry Istanbul University, B59(1):75-92.

Kumar, P., Pandey, P.C., Singh, B.K., Katiyar, S., Mandal, V.P., Rani, M., Tomar, V., Patairiya, S., 2016. Estimation of Accumulated Soil Organic Carbon Stock in Tropical Forest Using Geospatial Strategy. The Egyptian Journal of Remote Sensing and Space Sciences, 19:109-123.

Lucieer, A., de Jong, S.M., Turner, D., 2014. Mapping landslide displacements using Structure from Motion (SfM) and image correlation of multi-temporal UAV photography. Progress in Physical Geography, 38(1): 97-116.

Matese, A., 2020. Editorial for the Special Issue "Forestry Applications of Unmanned Aerial Vehicles (UAVs)". Forests, 11, 406.

Schäfer, E., Heiskanen, J., Heikinheimo, V., Pellikka, P., 2016. Mapping Tree Species Diversity of a Tropical Montane Forest by Unsupervised Clustering of Airborne Imaging Spectroscopy Data. Ecological Indicators, 64: 49-58.

Selmi, E., 2009. Investigations on vertebrata fauna of Düzce-Efteni Lake (original in Turkish). PhD Thesis. Istanbul University, Institute of Natural and Applied Sciences, pp.165.

Shervais, K., 2015. Structure from Motion, Introductory Guide. Retrieved July 27, 2016, from https://www.unavco.org/education/resources/educati onal-resources/lesson/field-geodesy/modulematerials/sfm-intro-guide.pdf

Snavely, N, Seitz, SM, Szeliski, R., 2008. Modeling the world from internet photo collections. International Journal of Computer Vision, 80(12): 189-210.

Srivastava, P.K., Mehta, A., Gupta, M., Singh, S.K., Islam, T., 2015. Assessing Impact of Climate Change on Mundra Mangrove Forest Ecosystem, Gulf of Kutch, Western Coast of India: A Synergistic Evaluation Using Remote Sensing. Theoretical and Applied Climatology 120 (3-4):685-700.
Steinaker, D.F., Jobb, E.G., Martini, J.P., Arroyo, D.N., Pacheco, J.L., Marchesini, V.A., 2016. Vegetation Composition and Structure Changes following Roller-Chopping Deforestation in Central Argentina Woodlands. Journal of Arid Environments, 133 (2016): 19-24.

Tang, L., Shao, G., 2015. Drone remote sensing for forestry research and practices. J. For. Res., 26(4):791-797.

Torresan, C., Corona, P., Scrinzi, G., Vall Marsal, J., 2016. Using Classification Trees to Predict Forest Structure Types from Lidar Data. Annals of Forest Research, 59 (1): 1-18.

Torresan, C., Berton, A., Carotenuto, F., Di Gennaro, S.F., Gioli, B., Matese, A., Miglietta, F., Vagnoli, C., Zaldei, A., Wallace, L., 2017. Forestry applications of UAVs in Europe: a review, International Journal of Remote Sensing, 38(8-10): 2427-2447.

Turk, Y., Boz, F., Aydın, A., Eker, R., 2019a. Evaluation of UAV usage possibility in determining the forest road pavement degradation: preliminary results. 3rd International Engineering Research Symposium (INERS'19), 05-07 September 2019, Düzce Turkey, pp. 630-633.

Turk, Y., Aydın, A., Eker, R., 2019b. Effectiveness of open-top culverts in forest road deformations: preliminary results from a forest road section, DüzceTurkey. 2nd International Symposium of Forest Engineering and Technologies, 04-06 September 2019, Tirana-Albenia, pp. 147-152.

Ullah, S., Farooq, M., Shafique, M., Siyab, M.A., Kareem, F., Dees, M., 2016. Spatial Assessment of Forest Cover and Land-Use Changes in the HinduKush Mountain Ranges of Northern Pakistan. Journal of Mountain Science, 13 (7): 1229-1237.

Ullman, S., 1979. The interpretation of structure from motion. Proc. R. Soc. London, Ser. B, 203: 405-426, doi:10.1098/rspb.1979.0006.

Vacca, G., Dessi, A., Sacco, A. 2017. The use of nadir and oblique UAV images for building knowledge. ISPRS Int. J. Geo-Inf., 6:393.

Yao, H., Qin, R., Chen, X., 2019. Unmanned aerial vehicle for remote sensing applications-a review. Remote Sensing, 11:1443.

Zhang, J., Hu, J., Lian, J., Fan, Z., Ouyang, X., Ye, W., 2016. Seeing the forest from drones: testing the potential of light-weight drones as a tool for longterm forest monitoring. Biological Conservation, 198:60-69. 